\section{P208 IMPACT OF MORNING SYMPTOMS EXPERIENCED BY COPD PATIENTS ON EXACERBATION RISK, RESCUE INHALER USAGE AND NORMAL DAILY ACTIVITIES}

doi:10.1136/thoraxjnl-2012-202678.269

M Small, S Broomfield, R Pollard, S Fermer. Adelphi Real World, Macclesfield, UK

Impact of morning symptoms experienced by COPD patients on exacerbation risk, rescue inhaler usage and normal daily activities Background Patients consider the impact of COPD on morning activities to be substantial. Evidence of the association of morning symptoms and the impact on the entire day with poor breathing control contributes to the understanding of their importance for managing COPD patients.

Objectives To quantify the impact of morning symptoms experienced by patients receiving inhaled corticosteroid plus long-acting $\beta_{2}$-agonist (ICS/LABA) by association with exacerbation frequency, rescue usage and impact on daily activities.

Methods Data were drawn from a real world study of consulting COPD patients in the USA and Europe in 2011. Results were tested for significance $(p<0.05)$ using Mann-Whitney and negative binomial regressions. Confounders included age, gender, BMI, comorbidities, severity, smoking status and adherence.

Results Of the 3790 patients in the study, 593 were receiving ICS/ LABA-only (+/-rescue). Of the 177 patients reported to experience morning symptoms, cough $(65.5 \%)$ and excess sputum $(53.1 \%)$ were the most common. Compared with patients without morning symptoms, these patients were associated with higher mean exacerbation frequency in the last 12 months ( 1.04 vs $0.63 p<0.001)$, rescue usage per day ( 0.58 vs $0.46 p=0.025)$ and daytime impact on a 7 -point Likert scale where 7 represents a constant impact (3.61 vs $3.00 \mathrm{p}<0.001)$.

Conclusion Morning symptoms were associated with significantly more impaired breathing control for patients treated with ICS/LABA-only therapy. The association implies morning symptoms are an important indicator when assessing the impact of $\mathrm{COPD}$ and their presence suggests that further therapeutic intervention may be necessary.

\section{P209 IMPACT OF PATIENT SATISFACTION WITH THEIR MAINTENANCE INHALER ON TREATMENT COMPLIANCE AND HEALTH OUTCOMES IN CHRONIC OBSTRUCTIVE PULMONARY DISEASE: AN ANALYSIS OF REAL-WORLD CLINICAL PRACTISE IN EUROPE}

doi:10.1136/thoraxjnl-2012-202678.270

${ }^{1} \mathrm{H}$ Chrystyn, ${ }^{2} \mathrm{M}$ Small, ${ }^{2} \mathrm{G}$ Milligan, ${ }^{3} \mathrm{~V}$ Higgins, ${ }^{4} \mathrm{E}$ Garcia Gil, ${ }^{4} \mathrm{C}$ Karakurum. ${ }^{1}$ University of Huddersfield, Huddersfield, UK; ${ }^{2}$ Adelphi Real World, Macclesfield, UK; ${ }^{3}$ Adelphi Real World, New York, NY, USA; ${ }^{4}$ Almirall SA, Barcelona, Spain

Introduction and objective Compliance with prescribed treatment is often suboptimal in patients with chronic obstructive pulmonary disease (COPD). This analysis examined the relationships between inhaler satisfaction, compliance and health outcomes.

Methods Data were analysed from a large, cross-sectional survey of real-world clinical practise conducted in five European countries. Respiratory specialists and primary care physicians provided information on six consecutive patients with COPD (aged $\geq 40$ years with history of smoking). The same patients were then asked to voluntarily complete a self-assessment form. Physicians scored patient compliance with prescribing instructions (5-point Likert scale: $1=$ 'not at all compliant'; $5=$ 'fully compliant') and patients rated overall satisfaction with their maintenance inhaler (7-point Likert scale: $1=$ 'not at all satisfied'; $7=$ 'very satisfied'). Health outcomes assessments included exacerbations, the modified Medical Research Council dyspnoea scale, the EuroOoL (EQ-5D) instrument and the Jenkins Sleep Questionnaire. Sequential regression was used to analyze the relationship between inhaler attributes and overall satisfaction. Least-squares regression and additive models were used to analyze the relationships between inhaler satisfaction, compliance and health outcomes.

Results Data were included for 1443 patients for whom selfcompleted and matched physician-completed record forms were available. The majority of patients $(71.8 \%)$ were male; mean age was 65.2 years. Very few patients $(0.7 \%)$ were 'not at all compliant' with their physician's prescribing instructions, whilst $33.3 \%$ were 'fully compliant'. Most patients (75.1\%) were more satisfied with their inhaler than not; $6.6 \%$ were 'very satisfied'. Key attributes influencing satisfaction related to durability, ergonomics and ease of use. There was a significant association between inhaler satisfaction and compliance $\left(\chi^{2}-\mathrm{df}=89.7 ; \mathrm{p}<0.001\right)$. Other factors related to greater compliance, though to a lesser degree, were fewer maintenance drugs $\left(\chi^{2}-\mathrm{df}=17.7 ; \mathrm{p}<0.001\right)$ and male gender $\left(\chi^{2}-\mathrm{df}=2.9 ; \mathrm{p}<0.05\right)$ Severity of breathlessness, age and ethnicity were not significantly associated with compliance $(p>0.05)$. Higher compliance scores were significantly associated with better health outcomes (Table). There was also a direct association between inhaler satisfaction and better health outcomes (exacerbations and EQ-5D, p<0.001).

Conclusions Inhaler satisfaction appears to be significantly associated with COPD treatment compliance, and patients with greater compliance experience better health outcomes, including less frequent exacerbations.

Abstract P209 Table 1

\begin{tabular}{|c|c|c|c|}
\hline & \multicolumn{3}{|c|}{ Association with health outcomes } \\
\hline & $\mathbf{N}$ & $\mathbf{R}^{2}$ & p-value \\
\hline \multicolumn{4}{|c|}{ Relationship between health outcomes and increasing compliance score } \\
\hline Fewer exacerbations in past 12 months ${ }^{a}$ & 1403 & 0.037 & $<0.001$ \\
\hline $\begin{array}{l}\text { Fewer exacerbations managed through } \\
\text { hospitalisation in past } 12 \text { months }\end{array}$ & 1084 & 0.025 & $<0.001$ \\
\hline Lower mMRC dyspnoea scale score ${ }^{a}$ & 1419 & 0.031 & $<0.0001$ \\
\hline Higher EQ-5D score ${ }^{b}$ & 1422 & 0.035 & $<0.0001$ \\
\hline Lower Jenkins Sleep Index & 1402 & 0.064 & $<0.0001$ \\
\hline \multicolumn{4}{|c|}{ Relationship between health outcomes and increasing inhaler satisfaction } \\
\hline Fewer exacerbations in past 12 months ${ }^{a}$ & 944 & 0.032 & $<0.001$ \\
\hline Higher EQ-5D score ${ }^{b}$ & 959 & 0.030 & $<0.001$ \\
\hline
\end{tabular}

\section{P210 ARE SPUTUM AND BLOOD BIOMARKERS OF INFLAMMATION REPEATABLE IN STABLE COPD?}

doi:10.1136/thoraxjnl-2012-202678.271

BL Barker, V Mistry, M Pancholi, CE Brightling, M Bafadhel. Institute for Lung Health, Department of Infection, Immunity and Inflammation, University of Leicester, Leicester, United Kingdom

Background Spirometry is a commonly used end-point in COPD clinical trials and there is evidence that spirometric values are reproducible in COPD patients. COPD is heterogeneous and differences in biomarkers of pulmonary and systemic inflammation between patients can be identified. Currently limited short-term reproducibility is available in stable COPD.

Aims Assess repeatability of commonly used clinical measures in subjects with stable COPD over 3 and 6 months.

Methods Subjects with COPD were enrolled into an observational study and were reviewed at stable visits after 3 and 6 months. Spirometry, blood [peripheral blood total white cell and differential cell counts] and sputum [sputum differential cell counts (\%)] markers of inflammation were repeated at each visit. Repeatability of 